\title{
An Empirical Assessment and Theoretical Model of Student Productivity in Learning
}

\author{
Reza G. Hamzaee \\ Missouri Western State University, St. Joseph, USA \\ Seth A. Parker \\ Federal Reserve Bank of Kansas City, Kansas City, USA
}

\begin{abstract}
In response to an applied learning problem encountered by most students, this research is motivated to establish a theoretical economic model of knowledge production. The research problem here lacks enough productivity in many students' academic preparation and learning. Hence, a strong need for applied learning has also motivated this study. The authors did a major survey on MWSU campus to compile data for testing their mathematical-economic model of productivity involving an isocost-isoquant approach. Some designated research questions in this study are: How is productivity in preparation and learning defined? What are students' perceptions of instructors' roles in their productivity? What reliable productivity/learning model could be offered, which would be statistically fit and significant? Among several survey-based findings, in response to a question "What role should instructors play in students' productivity?". The majority of the respondents (80\%) responded: "Teaching most responsibly, clearly, and with enough emphasis on the most important components of materials". Applied learning is an economic return to an efficient investment in human capital, which would empower one to influence one's environment at large. An objective (post-theory) learning assessment will be another emphasis in this research project.
\end{abstract}

Keywords: applied learning, knowledge, production, function, model, human capital, assessment

\section{Introduction}

The topic of productivity is of the utmost importance to institutions and students alike. As the Rand Corporation notes, colleges and universities are using productivity improvement methods to cope with resources that are limited (Rand Corporation, 1997). Yet the discussion, from the perspective of institutions of higher education, focuses on cost savings and efficiently utilizing scarce resources. This research will focus on productivity from the student's perspective. This is important because the productivity has a significant effect on the future careers and graduate programs for students.

The research problem, motivating this study, is a lack of enough productivity in many students' academic preparation and learning, which would lead to an under-preparation for prospective challenging careers and/or

Reza G. Hamzaee, Ph.D., Professor of Economics \& Applied Decision Sciences, Department of Economics, Missouri Western State University (Walden University).

Seth A. Parker, M.S., Economic Analyst, Federal Reserve Bank of Kansas City.

Correspondence concerning this article should be addressed to Reza G. Hamzaee, Department of Economics, Missouri Western State University (Walden University) 4525 Downs Drive, St. Joseph, MO 64507, USA. E-mail: hamzaee@ missouriwestern.edu; reza.hamzaee@waldenu.edu. 
success in graduate programs. The objective of this research is to develop and empirically assess a theoretical model of student production in learning, including a production function of students' preparation and learning.

The research questions here are:

- How is productivity in preparation and learning defined?

- What are the main explanatory variables of productivity in learning?

- What are students' perceptions of productivity?

- What are students' perceptions of learning?

- What are students' perceptions of the most influential factors accounting for productivity?

- What are students' perceptions of the most influential factors accounting for learning?

- How could the expected quantity-quality standards of learning be effectively implemented?

- What are students' perceptions of instructors' roles in their productivity?

- What are students' perceptions of instructors' five most significant requirements for their better learning?

- What reliable productivity/learning model could be offered, which would be statistically fit and significant?

A set of hypotheses will be tested in this study as well. These include the following. Students perceive labor hours to be the main ingredient for high productivity and learning, and good note taking to be a significant factor. Active learning, effective attention and participation in class discussion are significantly influential in learning. Application of critical thinking by both instructors and students, and gradual (ongoing) preparation would enhance students' productivity and learning. Comprehensive reading-writing assignments and multiple-choice questions will increase students' understanding and learning significantly. Team preparation and student networking have significantly increased productivity and learning. A clear determination of objectives prior to teaching has enhanced students' learning significantly. Real-world and factual examples of the teaching subjects have made understanding of sophisticated subjects easier.

In the next section, a review of the currently available and relevant literature on the subject is presented, focusing on comparing and contrasting the positions of other researchers, and selecting a position or idea for building research. Following the literature review, a theoretical model including a production function will be developed, in which the hypothetical variables will be explained, and there will be discussion of advantages and disadvantages of marginal productivity versus average productivity measurements. A survey designed to assess and measure students' perceptions will follow, and a statistical examination through a log-linear regression model will be performed on the data. The results of the statistical procedures will be analyzed, after which a conclusion section will close the report.

\section{Literature Review}

Discussions of productivity in education are numerous, varied, and often confusing. There are many different schools of thought, but it may be helpful to functionally classify most researches into two groups. One would be the student perspective on productivity in learning, which will be discussed subsequently. While the other, more common, would be the institutional perspective. Some central concepts here are reducing unnecessary costs, making teachers more productive, and generally making institutions more efficient and effective. Poole (2005) provided a good example of this traditional focus. First he outlined some of the problems with current conceptions of productivity in higher education and ways in which to improve it. He broadly described trends in collegiate education, focusing on increasing tuition and institutional costs. A central 
problem here is the lack of incentives to reduce or control costs, which can lead to a misallocation of resources. In this vein, Poole (2005) indicated that the recent focus on financial assistance to students has created an environment where tuition costs garner the most attention, while the underlying cost reductions or productivity improvements are not considered.

Poole (2005) provided some clarity to the concepts of productivity in higher education as well. Productivity can be seen from a cost perspective or from a student value perspective. Student value represents the capabilities of graduating students. Therefore, if costs can be expanded more slowly than student improvement, productivity will increase. He went on to describe the familiar difference between efficiency and effectiveness in measures of productivity. This is a valuable construct for considering student productivity. A student may reach a desired educational outcome (effectiveness), while taking far longer than normal to reach the desired outcome (efficiency).

Because Poole's (2005) concern with productivity is mostly institutional, he does not strongly consider the role that student productivity plays in the larger topic of educational productivity. At the heart of this discussion are four pragmatic reforms to improve productivity in higher education. They are privatization, decentralization, improving student quality, and increased flexibility of faculty staffing. All these are essentially cost saving concepts.

In contrast to Poole (2005) and the traditional focus, Astin (1999) presented his theory of student involvement, essentially stating that increased student involvement will lead to better outcomes in education and learning, and that institutions adept at improving the involvement of students will be successful (p. 519). Most research in this field is focused on the institutional side of the equation. This view treats students as an intermediate device that receives inputs from educators and institutions and outputs learning, as measured by many different metrics and standardized tests (p. 519). Astin believes this is the wrong perspective to take.

Astin (1999, pp. 520-521) analyzed three traditional theories of student learning and productivity, the subject-matter theory, the resource theory, and the individualized (eclectic) theory. The first believes student learning to be a function of exposure to the right type and amount of subject matter. The second sees student learning as a function of having the right pieces or resources in place for students. The third sees student learning as a function of flexible and tailored learning approach unique to each pupil. Astin discussed problems with all these theories. Problems of implicit conceptions of students as non-active receptors of knowledge, a one-way flow of information and ideas, cost restrictions, and blind accumulation of resources without regard for their value or use are his most prominent concerns here.

In distinction to these theories, is the theory of student involvement, which has five parts: (1) The definition of involvement is the energy, both mental and manual labor, that students put into educational endeavors; (2) Student involvement is variable along a sliding scale; (3) There are qualitative (i.e., comprehension of concepts) and quantitative (i.e., amount of study time) elements to involvement; (4) The amount and caliber of student involvement will determine how much a student learns and develops; and (5) A successful approach in schooling is one that heightens student involvement.

Astin (1999) described the effects of the theory of student involvement (p. 522). For any teaching endeavor to succeed in student learning, student involvement must be a central concern. The concentration of teachers should be the actions of the students and less on their own actions. This will manifest as less interest in accumulating resources and analyzing policies and methods. Students must be contributing members in the process of learning. 
Astin (1999) continued by citing supporting research on involvement and dropout rates. The more involved a student is, the less likely he is to drop out and vice versa (p. 523). Another factor cited is the type of school the student attends. Two-year schools have a higher dropout rate than four-year schools (p. 524). Other involvement factors that decrease the risk of dropping out are honors programs, student-faculty involvement, athletic involvement, academic involvement, living on campus, and involvement in student government (pp. 524-526). This research, mostly Astin's own, provides support for his view that student involvement is paramount to learning and educational success.

The important point for our research is that student involvement, which also implies student motivation, is a key factor in determining whether or not a student will be productive in learning. Investigating the amount of time that students invest in learning, as well as the frequency with which they invest that time (i.e., gradual preparation) will be important aspects.

Astin's (1999) theory promotes a different perspective on the learning and productivity issue. He focused more on students and finding ways of improving their productivity, which eventually leads to an improvement in the productivity of the institution.

Levin (1993) expounded on a student-centric view of production functions, which is particularly pertinent to our research. He made the case for much more strongly considering students in production functions. To Levin, there are many factors that influence educational outcomes, which are controlled by multiple parties. In other words, teachers and institutions are not the only parties involved; students play an essential part in educational results.

Levin (1993) discussed the challenges of formulating an accurate production function for education. A primary challenge is how students are identified, in a theoretical factory context, as workers or raw materials. Most traditional views about education have seen students as entities to which learning is applied (i.e., a raw material). But, as Levin notes, no one can learn from a student, they must do that themselves. Institutions and teachers can only provide information, guidance, and tools for learning. Levin holds that the student to institution relationship is not a traditional production relationship, precisely because students must find value in learning and produce knowledge for themselves. Yet some input or effort is also required from instructors and institutions. Therefore students are both workers and raw materials.

Levin (1993) referenced a conventional method of improving outcomes as the "intensification" method. This is essentially a teacher developing more stringent standards, more harsh punishments, and more direct oversight. Yet, when students are seen in their unique position as both producer and material, the paramount importance of students' drive and perceptions becomes apparent. Levin further noted the value of measuring the perceptions of students on multiple issues in education, including teaching methods, institutional organization, and practices in discipline.

Another conventional method of improving outcomes is the "professionalization" method, which allows teachers the freedom to tailor their methods to get better outcomes. Levin (1993) pointed out the underlying flaw in this method as the belief that instructors have some pent-up reserve of knowledge and wisdom on how to improve productivity and that they will act on it. He saw it as unreasonable to agree with neither of these assumptions.

Levin (1993) broadly outlined the effects of a more student-centric approach to education, instead of the "intensification" or "professionalization" methods. In this approach, student motivation is a key factor. When we view students in their unique place in education where they create learning for themselves, a focus on 
motivation is natural. Levin (1993) (as cited in Lieberman \& Miller, 1990; Rosenholtz, 1985) argued that this is exhibited in valuing the enthusiasms and opinions of students to a much greater degree. It would also mean affording students more freedom and flexibility in schooling, similar to the way that professors have autonomy in their work.

Yet another traditional conception of education that Levin attacks is time. His primary argument is that the ways in which time is utilized and allocated could and should be more variable. This would theoretically result in better and more accurate allocations of time, which will lead to better outcomes and increased productivity.

The importance of students, as Levin (1993) pointed out, has not been considered properly, and a more student-centric approach will lead to more productivity and better outcomes in education. Levin underscored the importance of student motivation and perceptions, which will be further studied in our research.

From Levin (1993), we understand, among other things, that more intellectual energy should be applied in studying students' role in educational production. In this vein, the research of Walberg, Fraser, and Welch (1986) tested data from the National Assessment in Science (1981-1982) to determine the validity of a model of educational productivity. The educational productivity model of Walberg contains nine factors that are: (1) ability or prior achievement; (2) age; (3) motivation or self concept as indicated by personality tests or willingness to persevere on leaning tasks; (4) quantity of instruction; (5) quality of instructional experience; (6) home environment; (7) the classroom of school environment; (8) the peer group environment; (9) the classroom or school environment; and (10) the mass media, indicated by TV watching (p. 133).

The researchers found that the nine factors in Walberg's theory were more closely linked to student productivity then socio-economic factors, and generally supported the validity of Walberg's (1983, p. 133) theory.

This research showed that outcomes in education are better explained by multiple variables than any single factor. This is indicated by the fact that a less than proportionate change in learning outcomes is seen when a one standard deviation change occurs in any factor. Additionally, all of the factors in Walberg's (1983, pp. 133-134) theory are related to student productivity. An implication for our study here is that a significant number of variables should be considered to yield useful information.

The study shows that those students who start out with strength in one of the factors are likely to be strong in other factors. This is evidenced by the fact that there is colinearity among the factors. The importance of multiple variables is again supported here, because the data suggest that strength in factors does not occur singularly.

In the Walberg (1986) model, there are several fixed factors that significantly forecast students' intellectual performance. These are ability, home environment, gender, and race (p. 137). But, there is encouraging information that educators have the ability to increase student productivity and learning outcomes. Walberg et al. (1986) noted that six factors are seen to have a positive connection to both achievement and attitude in students. These were: capability, initiative, feelings on the instructor, homework volume, atmosphere of the classroom, and atmosphere of the home. Four of those factors (initiative, feelings on the instructor, homework volume, and atmosphere of the classroom) are firmly in the control of teachers and educational institutions to alter and change (pp. 137-138). This research provides some hard data in determining the influential variables in student learning and productivity, and exhibits one aspect that our research will investigate.

Astin (1999), Levin (1993), and Walberg et al. (1986) presented research with the common thread of 
student focus, but there are some differences among them. Astin argued that student involvement is paramount to student productivity, learning, and success, while Walberg et al. found that their nine factors provide an accurate picture of student productivity, learning, and success. It is important to note that implicit in Astin's concept of student involvement, are some of the factors which Walberg et al. find to be important, including student motivation. Levin concentrated on more accurately devising a production function that properly considers the role and importance of students. Yet, Levin also indicated that student motivation and even perceptions are valuable factors to consider.

A final observation that Poole (2005) makes is the obvious fact that productive colleges and universities will impact society in a meaningful and valuable way. This is one of our central research problems that we want to acknowledge. As previously noted, an increase in productivity from the institutional, and especially the student side can lead to societal change on a large scale.

\section{Theoretical Productivity Model}

\section{An Isoquant - Cost Approach}

In theory, students behave according to the following theoretical model depicted in Figure 1. The isoquant, representing all the combinations of the quantities of two groups of resources which render the same level of output, $Q t$, within a certain time frame, given all other relevant factors are held constant. It can be formulated as:

where:

$$
Q t=f(G H t, L H t ; T E C H t)
$$

$t=$ academic semesters, $1,2, \ldots, k$, in which a student may take courses and work for income;

$Q t=$ the quantity of student's desired output, measured by real income to be produced at time $t$;

$G H t=G t \times H t$

$G t=$ grade points at time $t$;

$T t=$ per hour tuition at time $t$;

$H t=$ hours of course work taken at time $t$;

$L H t=$ number of labor hours worked to make income at time $t$;

$T E C H t=$ technology or methods of studying and learning (a shifting factor for the two-dimensional production function).

$$
(T t \times H t)+(W t \times L H t)=B t
$$

Equation (2) can be re-organized into the following total tuition cost at time $t$ :

$$
T t \times H t=B t-(W t \times L H t)
$$

where:

$W t=$ hourly income at time $t$;

$B t=$ student's budget in period $t$.

- If $B t>$ or $=W t \times L H t$, the student would have some savings and/or some other sources of funds for his/her education (such as government or private scholarship, family contributions to his/her education expenses, etc.);

- If $B t<W t \times L H t$, the student would have enough income to pay for his/her education and still have some left for other things;

- If $B t=W t \times L H t$, the student's budget is exactly the same as his/her income.

The optimal choice of work hours and an indexed course hours $(G H t=G \times H)$ committed to at the end of 
time $t$, would be realized at point $e$ in Figure 1. The optimal output, $Q$, is in fact a measure of real income of the student, given the optimal allocation of his/her time.

The above model could be applied when a control group's continuous actions in taking classes and/or working for income are available. That is another task to be fulfilled later.

In practice, to find out more about students' productivity, a survey instrument, as presented in the next section, will be used to see how students define productivity in studying and also learning.

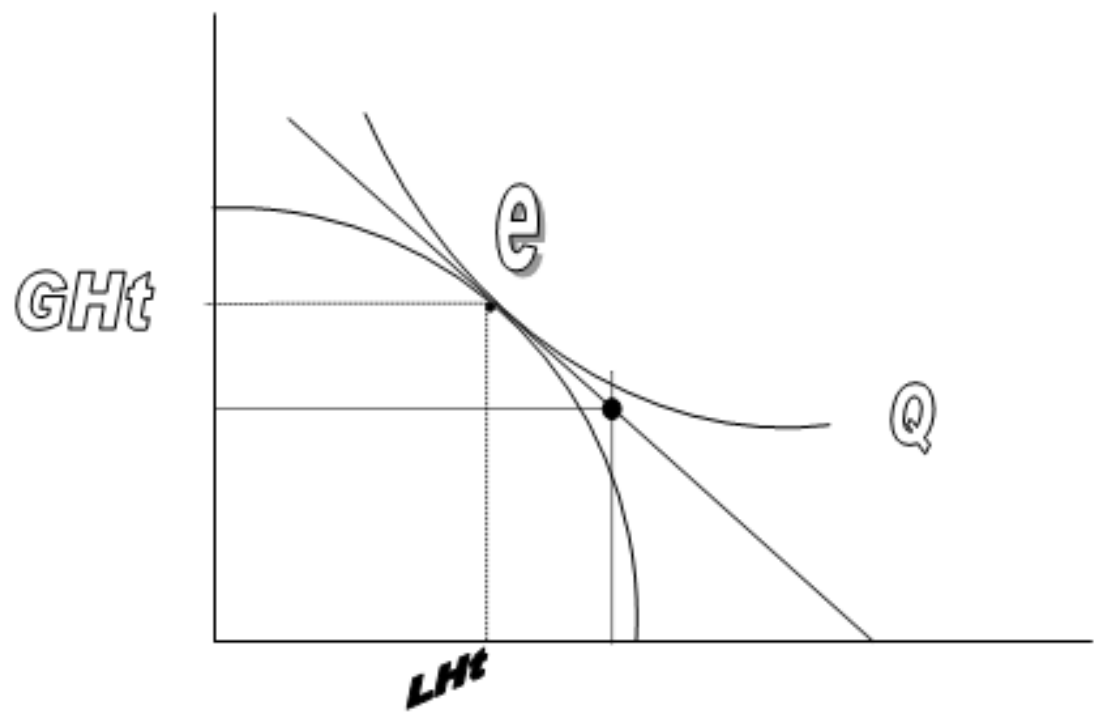

Figure 1. Student's time budget to work and passing courses.

\section{Student Survey Analysis}

\section{The Survey Instrument and the Results}

The surveys were administered to a wide variety of disciplines and all grade levels of students (freshman to senior). The disciplines of the classes in which the survey was administered were education, physical education, mathematics, political science, economics, freshman honors colloquia, and biology. The target population is all students of a regional Midwestern University, and the sample 176. The survey instrument and the corresponding results are presented below.

(1) How is productivity in studying defined?

a. Being able to plan to study the most important material;

b. Being able to study regularly;

c. Being able to study the text material assigned by the instructor;

d. All of the above.

A majority of students (74\%) selected "All of the above", indicating that planning to study the most important material, regular studying, and studying the text material assigned by the instructor are all part of the definition of productivity in studying (see Appendix Figure A1, labeled "Question 1").

(2) How is productivity in learning defined?

a. An average number of pages (or quantity) learned per hour of labor (study hour);

b. An average quantity of learning of anything per hour of labor;

c. Both a and b; 
d. All of the above must explain productivity, plus an earned skill of application of critical thinking, which would require more thinking of thinking, and carefully considering all aspects of an issue in a comprehensive analysis of each issue.

A majority (62\%) said that productivity in learning includes average number of pages learned per hour of labor, average quantity of learning anything per hour of labor, and an earned skill of application of critical thinking. The responses to this question suggest a fairly holistic view of learning productivity on the part of students studying (see Appendix Figure A1, labeled "Question 2").

(3) What are the main explanatory variables of productivity in learning?

a. Number of hours of labor allocated to studying;

b. A good set of lecture notes;

c. A good textbook;

d. Good, relevant, and clear instruction from the instructor.

The results on question 3 were more mixed, $46 \%$ said that good instruction from the instructor is the main variable in productivity in learning, $27 \%$ said that number of hours spent studying is the most important variable, and $23 \%$ said that a good set of lecture notes is the most important variable. Only $4 \%$ cited a good textbook as the most important variable. This indicates that students perceive instructors to have the greatest impact on their productivity in learning. Educators must consider this information further in relation to methods of increasing student productivity in learning studying (see Appendix Figure A1, labeled "Question 3").

(4) What are your perceptions of your learning productivity? I need to...

a. Have more time to study;

b. Have more money to be able to study more than work;

c. Learn more comprehensively than just for a grade;

d. Learn how to enjoy the learning experience and worry less about grades;

e. Do much better than what I am doing.

On question 4 students had mixed opinions. The largest portion (37\%) said that they need to learn more comprehensively than just for a grade. Similarly, $17 \%$ said that they needed to enjoy learning experiences more and worry less about grades. C and D, together totaling 54\% of responses, indicate that students focus on grades more than productivity. Twenty-one percent said they needed more time to study and $14 \%$ said they needed to have more money to be able to study more than work. Together, these two questions totaled $35 \%$ of responses. This indicates that while students do perceive time constraints, partially derived from the need to work for income, as a factor affecting their productivity, more students perceive their focus on grades rather than learning as a more important factor studying (see Appendix Figure A1, labeled "Question 4").

(5) What are your perceptions of your learning?

a. My actual learning is too poor;

b. I am doing sufficiently around an average level;

c. I am doing well;

d. I am doing very well;

e. I am doing excellent.

Question 5 produced a nearly perfect bell curve. It is important to note here the perceived level of learning increases as we move from answer "A" to " $\mathrm{E}$ ", with the later being the best, $37 \%$ said they were "doing well" in their learning, this is the average level, $27 \%$ said they were "doing sufficiently around an average level" and 
"doing very well" respectively, 4\% said their "actual learning is too poor", and 5\% said that they were "doing excellent". The results on this question are interesting as the vast majority of students placed themselves in the middle three categories. The researchers were expecting a higher concentration of answers in the "very well" and "excellent" column, as students tend to be somewhat biased on questions of their success and achievement studying (see Appendix Figure A1, labeled "Question 5").

(6) What are your perceptions of the most important variables affecting productivity in learning?

a. An adequate number of hours to study;

b. Satisfactory completion of prerequisite courses aiding in understanding and learning of new courses;

c. A well-organized and understandable set of lectures;

d. A well-designed set of study questions (relevant to the course learning objectives);

e. Employment of a highly applicable instructional technology.

Students indicated that the two most important factors affecting productivity in learning were good lecture notes (33\%) and good study questions (30\%). In contrast, $18 \%$ indicated that an adequate number of hours to study and $17 \%$ perceived completion of prerequisite courses were the most important factors. Instructional technology was indicated to be the least important factor influencing productivity in learning. The responses here are somewhat contradictory to our hypothesis that students perceive hours of studying as a significant variable affecting productivity. Indeed it was secondary to both good lecture notes and good study questions for studying (see Appendix Figure A1, labeled "Question 6").

(7) How could some sorts of expected quantity and quality standards of learning be effectively defined and implemented by the instructor?

a. Assignment of easier supplemental reading at home, which is not covered in lectures;

b. Instructor's requirement and implementation of critical thinking in all lectures, which would require more thinking of thinking, and carefully considering all aspects of an issue in a comprehensive analysis of each issue;

c. A rewarding policy for students' active participation in class discussions;

d. A rewarding policy for students' punctuality and $100 \%$ class attendance;

e. An applied game design to bring fun to class.

The majority (50\%) of students said that a requirement and implementation of critical thinking is the best way of defining and implementing quantity and quality standards.

The authors are surprised by the responses to this question, specifically the concentration of responses on critical thinking. The question is on if students really believed this to be the best method for defining and implementing quantity and quality standards, or if the answer was chosen for other reasons, length or complexity for instance. Part of this skepticism is based on the view that the average student has not been introduced the concept of critical thinking in sufficient detail to fully understand what was being described by "implementation and definition of quantity and quality standards" studying (see Appendix Figure A1, labeled “Question 7").

(8) What role do instructors play in student productivity?

a. Teaching most responsibly, clearly, and with enough emphasis on the most important components of materials;

b. Assignment of easier supplemental reading at home, which is not covered in lectures;

c. Instructor's requirement and implementation of critical thinking in all lectures; 
d. A rewarding policy for students' active participation in class discussions;

e. A rewarding policy for students' punctuality and $100 \%$ class attendance.

Eighty percent of responses were for answer "A". This indicates that students overwhelmingly perceive instructors role in their productivity to be teaching clearly and emphasizing the most important material. Compared to other possible responses on this question, the concentration of responses on answer "A" is telling of students' perceptions. Other methods or tools instructors use seem to be viewed by students as less important than the quality and focus of the instruction itself. This is somewhat consistent with responses to question 3 , where $46 \%$ of students indicated that good instruction was the most important factor in learning productivity (see Appendix Figure A1, labeled "Question 8").

(9) In your opinion, which of the following also contribute to both your studying and learning productivity?

a. Effective student networking;

b. An applied game designed to bring fun to class;

c. A study guide provided by the instructor;

d. Regular class attendance;

e. The instructor's enthusiasm.

The two most common answers to the question of factors that contribute to studying and learning productivity were a study guide (48\%) and regular class attendance (23\%). Student networking and instructor enthusiasm were tied at $13 \%$, while an applied game only received 3\%. The concentration of answers on study guide is somewhat consistent with the responses on question 6, where $30 \%$ said that good study questions were important to productivity studying (see Appendix Figure A1, labeled "Question 9").

Open-ended questions:

For some qualitative implications, the following two extra open-ended questions can be also used for further depth in students' perceptions.

(10) What are students' perceptions of instructors' five most significant requirements for their better learning?

(11) What reliable productivity/learning model could be offered, which would be statistically fit and significant?

\section{A Student Evaluation Instrument}

Students are asked to evaluate each instructor by assigning a ranking from 1 to 5 , where 5 signifies the worst (poorest) and 1 signifies the best and exceptional. This evaluation instrument, which would assess instructional productivity in students' perception, will not be the focus of this survey. Yet, it would help for a more comprehensive prospective evaluation of teaching productivity, as perceived and assessed by students.

(1) The instructor's knowledge for this course is quite high;

(2) The instructor's lectures are organized, clear, and understandable;

(3) The instructor is generally well organized;

(4) The instructor appears to be enthusiastic and interested in what he/she is doing;

(5) The instructor's lectures incorporate enough of critical thinking;

(6) The instructor is skillful in engaging students in class discussion;

(7) The instructor is a good coach motivating students to study more and succeed; 
(8) The instructor's attitude towards students is very compassionate and friendly;

(9) The instructor's management of the course is very effective;

(10) The instructor is available for help and extra assistance to students;

(11) The tests and assignments are very relevant to the teaching material;

(12) I can apply what I am learning in this class to the real world issues and problems;

(13) The instructor's care and effective planning for applied learning are obvious;

(14) This instructor really cares about students' success and learning;

(15) Considering all the above 14 questions, how do you rank this instructor's overall efficiency and effectiveness, as compared and contrasted with all other instructors?

\section{Conclusions}

The authors in this paper have offered a summarized perspective of productivity improvement to be implemented at various colleges and universities in response to the usual academic resource limitations. A theoretical framework of productivity is presented, assuming that students are producers of their desired levels of real output or real income by mainly utilizing and allocating their labor hours to two main tasks of work (to make income) and hours of course work to accumulate prospective earning skills. There is also a technology of studying and learning skills that could contribute to their levels of productivity. The survey applied here is mainly about that method and technology along with how students' allocate their budgeted time in enhancement of their study and learning productivities. The following segment provides a summary of what have been the major findings (see Appendix Figure A1):

Questions 1, Answer D: "All the above", which included "Being able to plan to study the most important material", "Being able to study regularly", and "Being able to studying the text material assigned by the instructor".

Question 2, Answer D: "All the above", which included "An average number of pages (or quantity) learned per hour of labor (study hour)", "An average quantity of learning of anything per hour", and "An earned skill of application of critical thinking, which would require more thinking of thinking, and carefully considering all aspects of an issue in a comprehensive analysis".

Question 3, Answer D: "Good, relevant, and clear instruction from the instructor".

Question 4, Answer C: "I need to learn more comprehensively than just for a grade".

Question 5, Answer C: "I am doing well".

Question 6, Answer C: "A well-organized and understandable set of lectures".

Question 7, Answer B: "Instructor's requirement and implementation of critical thinking in all lectures, which would require more thinking of thinking, and carefully considering all aspects of an issue in a comprehensive analysis of each issue".

Question 8, Answer E: “A rewarding policy for students' punctuality and 100\% class attendance”.

Question 9, Answer C: "A study guide provided by the instructor".

\section{References}

Astin, A. W. (1999). Student involvement: A developmental theory for higher education. Journal of College Student Development, 40(5), 518-529.

Gage, N. L. (1961). The appraisal of college teaching: An analysis of ends and means. The Journal of Higher Education, 32(1), $17-22$. 


\section{AN EMPIRICAL ASSESSMENT AND THEORETICAL MODEL OF STUDENT PRODUCTIVITY}

Haertel, G. D., Walberg, H. J., \& Weinstien, T. (1983). A theoretical synthesis of constructs. Review of Educational Research, 53(1), 75-91.

Hamzaee, R. G. (2005). A survey and theoretical model of distance education program. International Advances in Economic Research, 11(2), 215-229.

Hanushek, E. A. (1979). Conceptual and empirical issues in the estimation of educational production functions. Journal of Human Resources, 14(3), 351-388.

Levin, B. (1993). Students and educational productivity. Retrieved from http://epaa.asu.edu/epaa/v1n5.html

Levin, H. M. (1991). Raising productivity in higher education. The Journal of Higher Education, 62(3), 241-262.

Poole, W. (2005). Improving productivity in higher education. Retrieved from http://www.stlouisfed.org/news/speeches/2005/4_07_05.html

Walberg, H. J., Fraser, B. J., \& Welch, W. W. (1986). A test of a model of educational productivity among senior high school students. Journal of Educational Research, 73(3), 133-139.

\section{Appendix A}

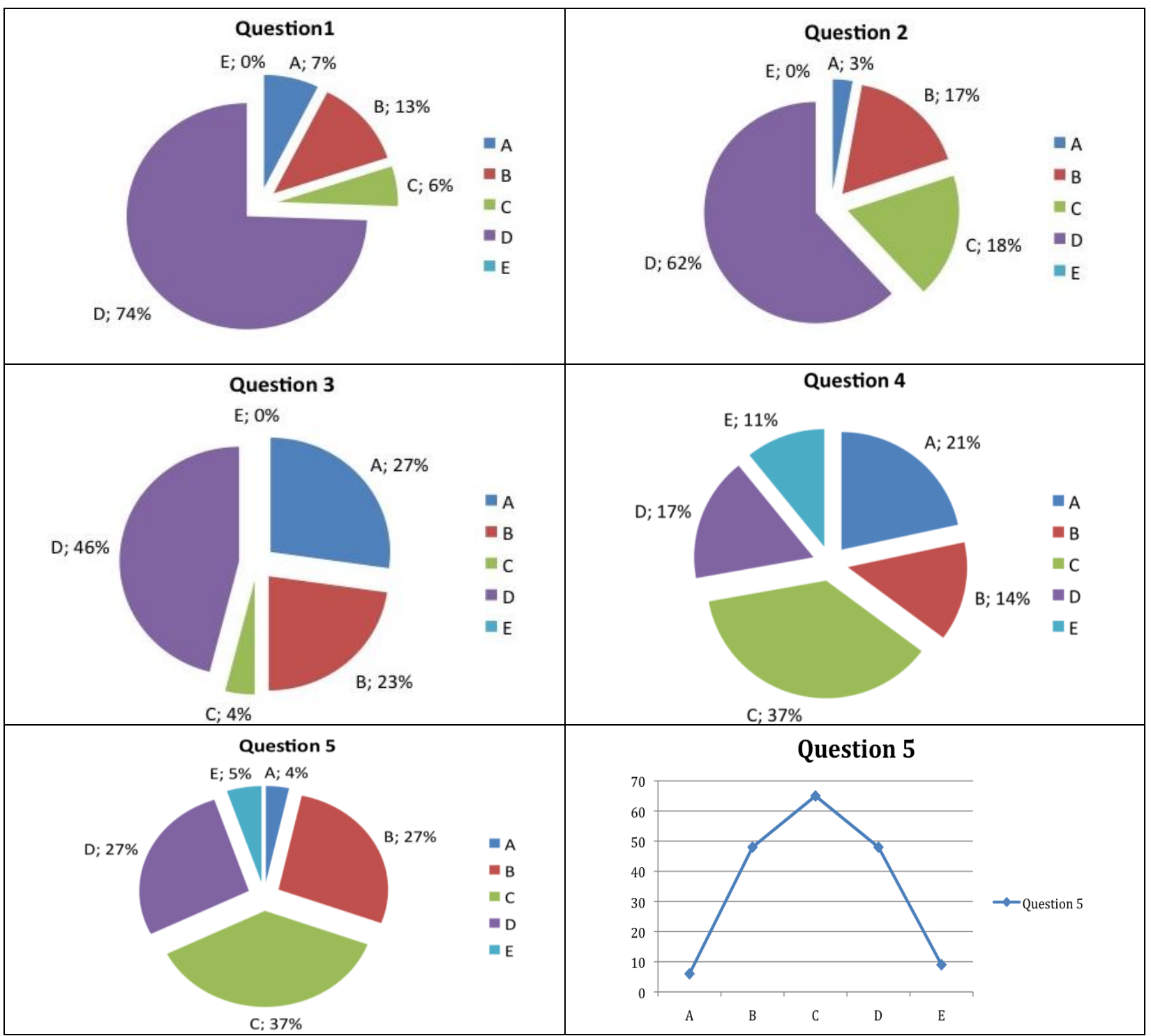




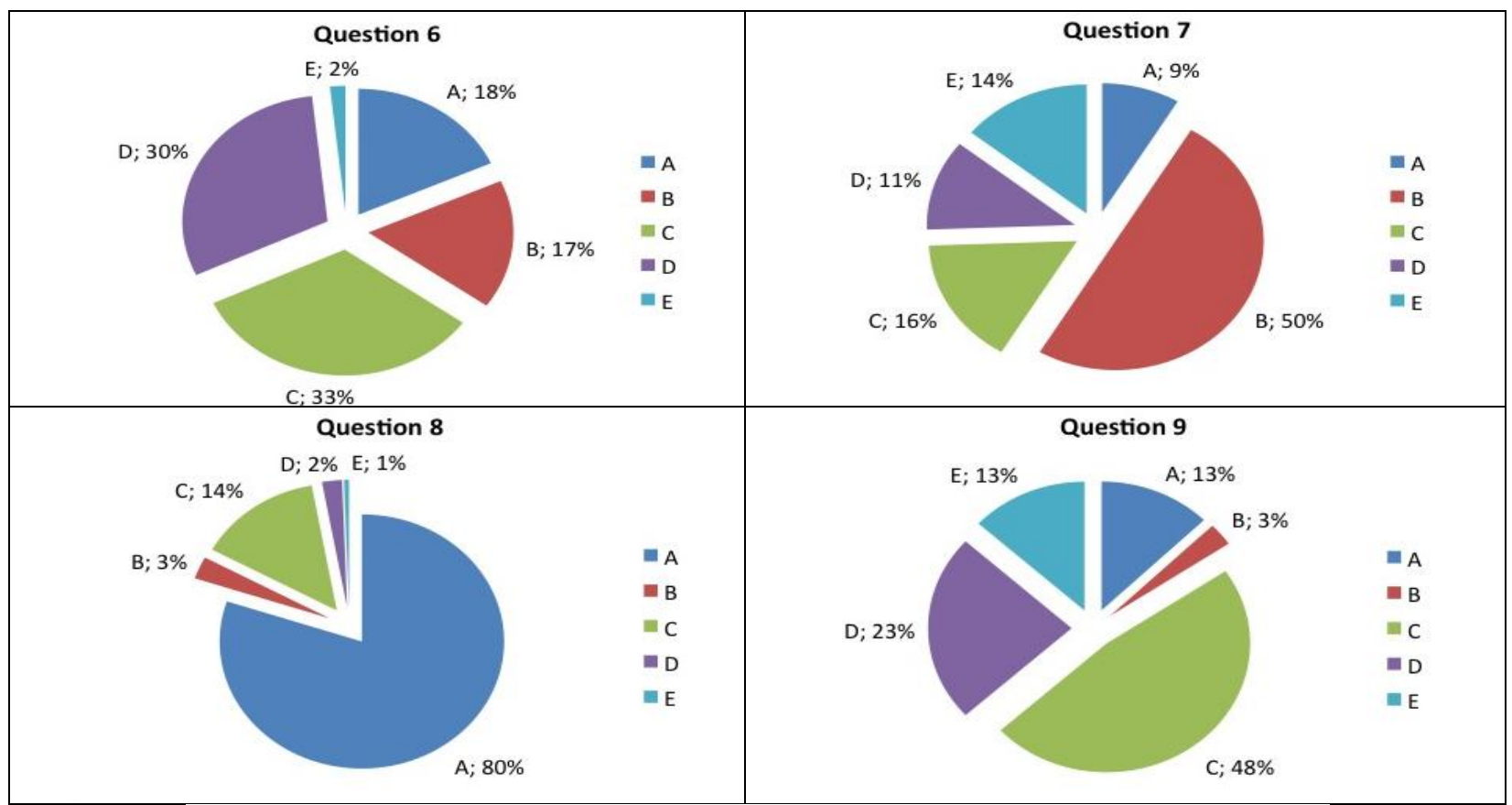

Highest Frequency Responses

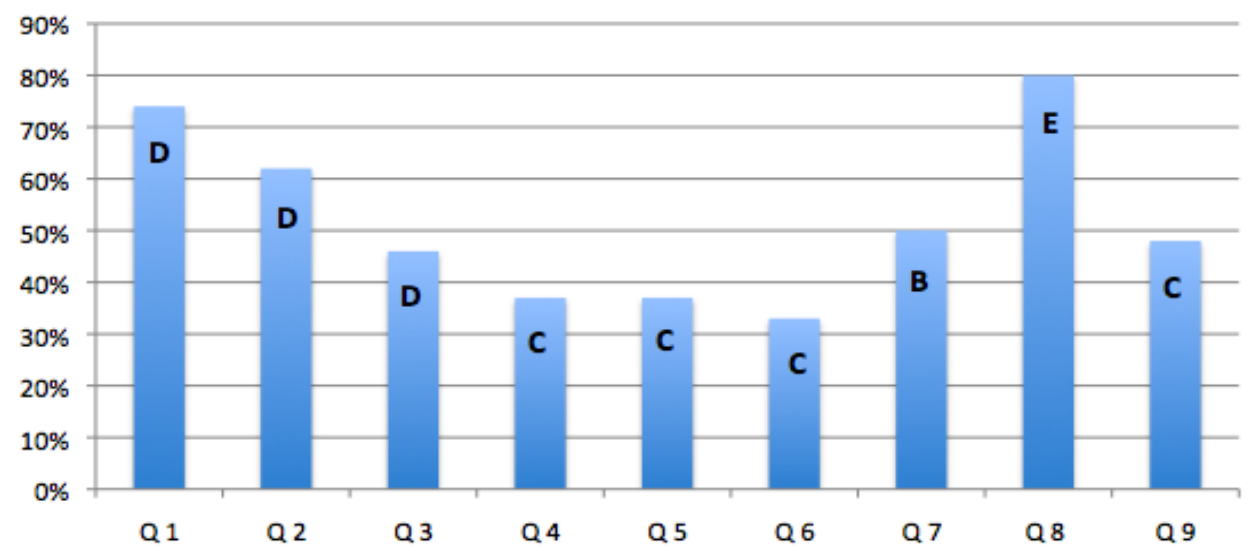

Figure A1. The survey responses, with the highest frequency. 